Risk-Return Trade-Off for European Stock Markets

Nektarios Aslanidis, Charlotte Christiansen and Christos S. Savva

CREATES Research Paper 2013-31 


\title{
Risk-Return Trade-Off for European Stock Markets *
}

\author{
Nektarios Aslanidis ${ }^{\dagger}$ \\ Universitat Rovira i Virgili, CREIP \\ Charlotte Christiansen \\ CREATES, Aarhus University \\ Christos S. Savva ${ }^{\S}$ \\ Cyprus University of Technology
}

October 8, 2013

\footnotetext{
${ }^{*}$ Christiansen acknowledges support from CREATES funded by the Danish National Research Foundation (DNRF78) and from the Danish Council for Independent Research, Social Sciences.

${ }^{\dagger}$ Universitat Rovira i Virgili, Department d’Economia, CREIP, Avinguda Universitat 1, 43204 Reus, Catalonia, Spain. Email: nektarios.aslanidis@urv.cat.

${ }^{\ddagger}$ CREATES, Department of Economics and Business, Aarhus University, Fuglesangs Alle 4, 8210 Aarhus V, Denmark. Email: CChristiansen@creates.au.dk.

${ }^{\S}$ Department of Commerce, Finance and Shipping, Cyprus University of Technology, P.O Box 50329, 3603 Limassol, Cyprus. Email: christos.savva@cut.ac.cy.
} 


\title{
Risk-Return Trade-Off for European Stock Markets
}

\author{
Abstract: This paper adopts dynamic factor models with macro-finance \\ predictors to revisit the intertemporal risk-return relation in five large Eu- \\ ropean stock markets. We identify country specific, Euro area, and global \\ factors to determine the conditional moments of returns considering the role \\ of higher-order moments as additional measures of risk. The preferred combi- \\ nation of factors varies across countries. In the linear model, there is a strong \\ but negative relation between conditional returns and conditional volatility. \\ A Markov switching model describes the risk-return trade-off well. A num- \\ ber of variables have explanatory power for the states of the European stock \\ markets.
}

Keywords: Risk-return trade-off; Dynamic factor model; Markov switching; Macro-finance predictors; Higher order moments

JEL Classifications: C22; G11; G12; G17 


\section{Introduction}

The relationship between the conditional return and conditional variance of asset returns, also referred to as the risk-return relation, has key relevance in areas within financial economics such as optimal portfolio choice and risk analysis. For instance, the Intertemporal Capital Asset Pricing Model (ICAPM) suggests that the conditional expected excess return on the stock market should vary positively with the market's conditional volatility. The literature testing the ICAPM relation documents that the relation is unstable and varies substantially over time; for recent contributions see Ludvigson and Ng (2007), Ghysels, Santa-Clara, and Valkanov (2005), and Brandt (2010) among others.

The present paper contributes to the existing literature as follows. We investigate the risk-return relation for five large European stock markets; France, Germany, Italy, Switzerland, and the UK. So far, little attention has been given to Europe in this respect as most studies focus on the US markets. From a methodological point of view, our work is related to Ludvigson and $\mathrm{Ng}$ (2007) who use a dynamic factor approach to test for the risk-return relation with US stock market data. As shown by Stock and Watson (2002) and others, dynamic factor models can usefully summarize the information from a large number of macro-finance series by a relatively small number of estimated factors. Indeed, recent approaches in the finance literature incorporate valuable information from large sets of macro-finance data to predict asset returns, cf. Ludvigson and Ng (2007), Goyal and Welch (2008), and Christiansen, Schmeling, and Schrimpf (2012).

In line with this intuition, we initially estimate the conditional return and conditional variance of excess stock market returns using factor-augmented models. Further, we let the risk of the stock markets be characterized by two 
additional higher order risk measures, namely the conditional skewness and conditional kurtosis. There is now ample empirical evidence showing that importance of higher-order moments in asset pricing; e.g., Harvey and Siddique (2000) argue that risk averse agents prefer positive skewness to negative skewness, and propose an asset pricing model that incorporates conditional skewness. Theodossiou and Savva (2013) show that it is important to take skewness effects into account when investigating risk-return trade-off. The factors are obtained as follows. First, we estimate country specific factors using a data set of macro-finance variables for each country separately. Second, we use Euro-area macro-finance variables to identify Euro-area factors. Third, we extract US factors from a US data base of macro-finance variables, also denoted global factors. After estimating factor-augmented models for the conditional return, conditional variance, conditional skewness, and conditional kurtosis, we ultimately estimate the relation between the risk and return. So, we add to the literature by investigating the effects upon the riskreturn relationship from using three different sets of factors (local, regional, and global) to obtain the conditional returns and conditional volatilities. In addition, we allow for skewness and kurtosis risk.

We further contribute to the literature by the way that the risk-return relationship is investigated. Firstly, we use a simple linear model similar to Ludvigson and $\mathrm{Ng}$ (2007). Secondly, we allow the state of the economy to have an effect on the risk-return relation. Initially, we do this by adding a binary indicator for recession periods to the risk-return regression. Subsequently, we let the data determine the states endogenously, namely by using a Markov switching model for the risk-return trade-off. This analysis is in line with the conditional ICAPM where the state of the economy approximating investment opportunities is also important in asset pricing, 
cf. Merton (1973), Guo and Whitelaw (2006), Lustig and Verdelhan (2012), Nyberg (2012)

The empirical results are as follows. We use monthly data from 1986 to 2012. For each country, the strength of the simple linear risk-return tradeoff varies according to which factors are used to calculate the conditional moments of returns. We use the relevant conditional returns, volatilities and higher order moments onwards. Linear risk-return regressions show that there is a negative relation between contemporaneous volatility and return. The risk-return trade-off is only slightly different across the business cycle. Further, the Markov switching model describes the risk-return relation well. The behavior in the most common state is similar to that in the linear model. The effect from the volatility is weaker in the unusual state. A number of variables help us explain which state the stock market is at. Overall, the European stock markets have very different risk-return trade-off behavior than the US stock market.

The structure of the remaining part of the paper is as follows. We introduce the data in Section 2 after which we explain the econometric framework in Section 3. The empirical results are found in Section 4 followed by the conclusion in Section 5. Various details are delegated to an Internet Appendix.

\section{Data}

We focus on the stock markets of five large European economies, namely France, Germany, Italy, Switzerland, and the UK. The data frequency is monthly with the sample covering the period from 1986M02 to $2012 M 05$. 


\subsection{Realized Risk Measures}

We use three risk measures, namely the realized volatility, realized skewness, and realized kurtosis. To calculate the monthly realized volatility we use daily observations. The stock log-returns are obtained from the DataStream total return local currency stock indices. ${ }^{1}$ We use the 3 -month interbank rates as risk free rates. ${ }^{2}$ These are calculated into daily rates by the money market convention (i.e. by dividing the yearly rate by 360 ). We calculate the end-of-month realized volatility for month $t$ from daily excess returns, $y_{\tau t}$.

$$
V o l_{t}=\sqrt{\sum_{\tau=1}^{n_{t}} y_{\tau t}^{2}}
$$

where $n_{t}$ is the number of days in month $t$ and $\tau$ indicates the particular day of that month $\left(\tau=1, . ., n_{t}\right)$. We treat the realized volatility as an observable variable, cf. Andersen, Bollerslev, Diebold, and Labys (2003).

The realized skewness and realized kurtosis are also calculated from daily excess returns:

$$
S k_{t}=\frac{1}{n_{t}-1} \sum_{\tau=1}^{n_{t}}\left(\frac{y_{\tau t}-\overline{y_{t}}}{V o l_{t}}\right)^{3}
$$

and

$$
K u_{t}=\frac{1}{n_{t}-1} \sum_{\tau=1}^{n_{t}}\left(\frac{y_{\tau t}-\overline{y_{t}}}{V o l_{t}}\right)^{4}
$$

where $\overline{y_{t}}$ is the average daily excess return for month $t$.

\footnotetext{
${ }^{1}$ The DataStream symbols are: TOTMKFR (France), TOTMKBD (Germany), TOTMKIT (Italy), TOTMKSW (Switzerland), and TOTMKUK (UK).

${ }^{2}$ The DataStream symbols are: ECFFR3M (France), ECWGM3M (Germany), ECITL3M (Italy), ECSWF3M (Switzerland), and ECUKP3M (UK).
} 


\subsection{Explanatory Variables}

We use a large number of explanatory variables to extract the common factors. The sample contains a number of country-specific variables for each country; France 152, Germany 147, Italy 95, Switzerland 152, and the UK 127. We also obtain aggregate data for the Euro area (179 variables) and for the US (174 variables) to construct Euro area (regional) and US (global) factors, respectively. The series are selected judgmental to represent major categories of macro-finance time series: foreign sector, output and income, sales, orders, purchases, employment, labour cost, money, prices, exchange rates, confidence indicators, stock market indices, and interest rates and spreads. The variables are transformed to be stationary (taking logs and differences where appropriate) and standardized. Further details about the data are provided in the Internet Appendix. The choice of series is similar to the what has been used in e.g. Stock and Watson (2002).

\subsection{Business Cycle Data}

Lustig and Verdelhan (2012) find that expected stock returns are higher in recessions than in expansions. To address the issue, we make use of a business cycle indicator variable for each country. The business cycle data are taken from the Economic Cycle Research Institute (ECRI) following Schrimpf and Wang (2010). 


\section{Econometric Methodology}

\subsection{Conditional Return and Conditional Risk}

We estimate the conditional return and conditional risk (conditional volatility, conditional skewness, and conditional kurtosis) of excess stock market returns. The first stage of the modelling procedure is to estimate the common factors. Let $X_{t}^{l o c}$ denote a large vector $\left(N_{l o c} \times 1\right)$ of country-specific macrofinance variables, $X_{t}^{\text {Eur }}$ is a large vector $\left(N_{E u r} \times 1\right)$ of Euro area macro-finance variables, and $X_{t}^{U S}$ is a large vector $\left(N_{U S} \times 1\right)$ of US macro-finance variables. The macro-finance variables are related to the unobserved common factors according to

$$
X_{t}^{j}=\Lambda^{j} F_{t}^{j}+e_{t}^{j}, \text { for } j=l o c, \text { Eur, } U S
$$

where $\Lambda^{j}$ is an $N_{j} \times r_{j}$ matrix of factor loadings and $F_{t}^{j}$ describes the $r_{j}$ dimensional vector of unobserved common factors, where $r_{j}<<N_{j}$. The $N_{j} \times 1$ vector $e_{t}^{j}$ denotes the purely idiosyncratic errors that are allowed to be serially correlated and weakly correlated across indicators. ${ }^{3}$ The above equation reflects the fact that the elements of $F_{t}^{j}$, which in general are correlated, represent pervasive forces that drive the common dynamics of $X_{t}^{j}$. It is in principle not restrictive to assume that $X_{t}^{j}$ depends only on the current values of the factors, as $F_{t}^{j}$ can always capture arbitrary lags of some fundamental factors.

We follow Stock and Watson (2002) and Ludvigson and Ng (2007) and split the analysis in two stages. In the first stage, we retrieve the principal component estimates, $\widehat{F}_{t}^{j}$. To determine the composition of $\widehat{F}_{t}^{j}$, we also use

\footnotetext{
${ }^{3}$ This cross-correlation must vanish as $N$ goes to infinity. See Stock and Watson (2002) for a formal discussion of the required restrictions on the cross-correlation of the idiosyncratic errors.
} 
the squared factors $\left(\widehat{F}_{i, t}^{j}\right)^{2}\left(i=1, \ldots, r_{j}\right)$. The dimension of the common factor space, $r_{j}$, is selected using the BIC criterion with the maximum order for $r_{j}$ being set to 6 .

Let $y_{t}$ denote the excess stock market log-returns at month $t \cdot{ }^{4}$ In the second stage, we predict the excess stock market return using a linear factor augmented regression

$$
\begin{aligned}
\widehat{y}_{t} & =\alpha^{\mathbf{y}}+\beta_{1}^{\mathbf{y}} \widehat{F}_{t-1}^{l o c}+\beta_{2}^{\mathbf{y}}\left(\widehat{F}_{t-1}^{l o c}\right)^{2}+\gamma_{1}^{\prime \mathbf{y}} \widehat{F}_{t-1}^{E u r}+\gamma_{2}^{\prime \mathbf{y}}\left(\widehat{F}_{t-1}^{E u r}\right)^{2} \\
& +\delta_{1}^{\prime \mathbf{y}} \widehat{F}_{t-1}^{U S}+\delta_{2}^{\prime \mathbf{y}}\left(\widehat{F}_{t-1}^{U S}\right)^{2}+\phi^{\mathbf{y}} y_{t-1}+\theta^{y} X_{t}
\end{aligned}
$$

where $X_{t}$ includes any additional variables such as the country specific term spread, the country specific dividend yield, and the VIX volatility index.

The conditional volatility is estimated using a similar linear projection based upon the following factor augmented model by simply replacing $\widehat{y}_{t}$ with $\widehat{V o l}_{t}$ and the parameters are changed accordingly e.g. from $\alpha^{y}$ to $\alpha^{v}$. The conditional skewness $\left(\widehat{S k}_{t}\right)$ and conditional kurtosis $\left(\widehat{K u}_{t}\right)$ are also estimated using similar factor augmented models.

In the empirical analysis we select a more parsimonious specification for eq. (2) (for all four variables) by following a general-to-specific search (deleting the least significant regressor and re-estimating the regressions each time). The reported models are selected using the BIC and retaining only variables that are significant at the $1 \%$ level of significance. We investigate the effects of using no factors $\left(\beta_{1}^{i}=\beta_{2}^{i}=\gamma_{1}^{i}=\gamma_{2}^{i}=\delta_{1}^{i}=\delta_{2}^{i}=0\right)$, only local factors $\left(\gamma_{1}^{i}=\gamma_{2}^{i}=\delta_{1}^{i}=\delta_{2}^{i}=0\right)$, only local and Euro factors $\left(\delta_{1}^{i}=\delta_{2}^{i}=0\right)$, and all factors simultaneously for the risk-return relation $(i=y, v, s, k$, where

\footnotetext{
${ }^{4}$ With a slight misuse of notation letting $y_{t}$ denote monthly values in place of daily ones.
} 
$y$ is the return regression, $v$ is the volatility regression, $s$ is the skewness regression, and $k$ is the kurtosis regression).

\subsection{Risk-Return Regressions}

In the most simple setting, we consider the following risk-return relationship (e.g., Ludvigson and $\mathrm{Ng}$ (2007)) where the current conditional return is explained by its own lag and the current and lagged values of the conditional risk measures.

$$
\begin{aligned}
\widehat{y}_{t} & =c_{1}+c_{2} \widehat{y}_{t-1}+c_{3} \widehat{V o l}_{t}+c_{4} \widehat{V o l}_{t-1} \\
& +c_{5} \widehat{S k}_{t}+c_{6} \widehat{S k}_{t-1}+c_{7} \widehat{K u}_{t}+c_{8} \widehat{K u}_{t-1}+e_{t}
\end{aligned}
$$

Subsequently, we let the risk-return relationship depend on the business cycle. We use the binary variable $D_{t}$ to indicate if a country is in a recession at time $t$. Then the regression becomes

$$
\begin{aligned}
\widehat{y}_{t} & =c_{11}+c_{12} \widehat{y}_{t-1}+c_{13} \widehat{V o l}_{t}+c_{14} \widehat{V o l}_{t-1} \\
& +c_{15} \widehat{S k}_{t}+c_{16} \widehat{S k}_{t-1}+c_{17} \widehat{K u}_{t}+c_{18} \widehat{K u}_{t-1} \\
& +c_{19} D_{t}+c_{20} D_{t} \widehat{y}_{t-1}+c_{21} \widehat{D}_{t} \widehat{V o l}_{t}+c_{22} D_{t} \widehat{V o l}_{t-1} \\
& +c_{23} D_{t} \widehat{S k}_{t}+c_{24} D_{t} \widehat{S k}_{t-1}+c_{25} D_{t} \widehat{K u}_{t}+c_{26} \widehat{D}_{t} \widehat{K u}_{t-1}+e_{t}
\end{aligned}
$$

Lastly, we use the Markov switching model to describe the risk-return relationship. ${ }^{5}$ The intuition is that the relationship can vary over time, switch-

\footnotetext{
${ }^{5}$ For more details on the Markov switching method and its popularity in the finance literature, cf. e.g. Guidolin (2011).
} 
ing between two states such as the normal and the unusual state. To uncover this property, we let $s_{t}$ denote an unobservable state variable, which follows a first order Markov chain with transition probabilities

$$
\begin{aligned}
& \operatorname{prob}\left(s_{t}=1 \mid s_{t-1}=1\right)=p_{11} \\
& \operatorname{prob}\left(s_{t}=2 \mid s_{t-1}=2\right)=p_{22}
\end{aligned}
$$

that determine the persistence of each state. The first state is the most common, $p_{11}>p_{22}$. The Markov switching risk-return trade-off regression is then given by

$$
\begin{aligned}
\widehat{y}_{t} & =c_{1}^{s_{t}}+c_{2}^{s_{t}} \widehat{y}_{t-1}+c_{3}^{s_{t}} \widehat{V o l}_{t}+c_{4}^{s_{t}} \widehat{V o l}_{t-1} \\
& +c_{5}^{s_{t}} \widehat{S k}_{t}+c_{6}^{s_{t}} \widehat{S k}_{t-1}+c_{7}^{s_{t}} \widehat{K u}_{t}+c_{8}^{s_{t}} \widehat{K u}_{t-1}+e_{t}
\end{aligned}
$$

where the parameters are constant but different in the two states,

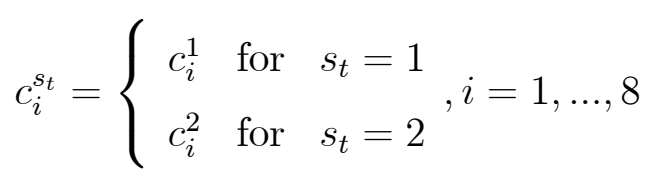

The residual follows a conditional normal distribution and its variance is state dependent: $e_{t} \sim N\left(0, \sigma_{s_{t}}^{2}\right)$ where

$$
\sigma_{s_{t}}^{2}=\left\{\begin{array}{lll}
\sigma_{1}^{2} & \text { for } & s_{t}=1 \\
c_{2}^{2} & \text { for } & s_{t}=2
\end{array}\right.
$$

Regime Classification Measures $(R C M)$ have been popularized, see e.g. Ang and Bekaert (2002) as a way to assess the quality of the model's performance. We adopt the following regime classification measure 


$$
R C M=100 \times \frac{4}{T} \sum_{t=1}^{T} \xi_{t / T}^{1} \xi_{t / T}^{2}
$$

where $\xi_{t / T}^{j}=\operatorname{prob}\left(s_{t}=j \mid \widehat{y}_{1}, \ldots, \widehat{y}_{T} ; \widehat{\theta}\right)$ for $j=1,2$ is the smoothed state probability. That is, the sample average of the products of the smoothed state probabilities. A perfect model will be associated with a $R C M$ close to 0 , while a model that cannot distinguish between regimes at all will have a $R C M$ close to 100 .

The Markov switching model has the advantage that it does not a priori choose a state variable. Instead, the regime classification in this model is probabilistic and determined by the data.

\section{Empirical Findings}

Throughout we use robust standard errors.

\subsection{Factor Estimation}

First we estimate a relatively large number of factors (10) for each country and choose the most important ones using the Bai and Ng (2002) criterion. The number of factors that sufficiently describe the data set is 6 for all countries. We present summary statistics of the estimated factors for each country as well as for the Euro area and the US. In particular, in Table 1 we report the accumulated fraction of variation in the data explained by the factors. The first factor explains the largest fraction of the total variation in the panel of data (which varies from $27 \%$ for Italy to $40 \%$ for the Euro area). The six first factors account for more than $80 \%$ of the variability in the data set of each country. To assess the persistence of the estimated factors we 
also report the first order autoregressive coefficient for each factor with the coefficients showing considerable heterogeneity ranging from small negative $(-0.18)$ to large positive (0.87). This is similar to Ludvigson and $\mathrm{Ng}(2007)$.

\subsection{Conditional Return and Conditional Risk Measures}

Now we present the best models for the conditional return and conditional risk measures for each country. The selection is made among a range of possible specifications that include local, Euro-area, and US factors along with their squared terms, as well as other important variables (the term spread and the dividend yield for the return equation, the VIX volatility index for the volatility equation, and all three variables for the skewness and kurtosis regressions) highlighted in the related literature, see for instance Guo and Whitelaw (2006).

Table 2 displays the results for the conditional return specification from eq. (2) using three specifications: with local factors, with local and Euro factors, and with local, Euro, and global factors. As we move from the restricted to the unrestricted regressions, there is an improvement in fit with the included regressors being similar which is an indication that our specifications search is robust. For France and Germany, local factors are important determinants of the estimated excess returns along with a number of US factors and the term spread. Similarly, the returns for Italy are predicted by local and US factors coupled with Euro squared terms. Switzerland and the UK are rather affected by the US factors along with some squared local factors (and squared Euro factors for the case of Switzerland). Finally, a typical financial ratio such as the dividend yield is an important predictor for fitted returns of all countries except from Germany, with the expected negative coefficient. The explanatory power of the factors is generally large as the 
adjusted $R^{2}$ statistic is large for all countries except for the UK.

Table 3 shows the factors that contain significant information about the conditional volatility according to the volatility version of eq. (2). As in the case of conditional returns, local and US factors along with their squared terms are important predictors for future conditional volatility of France, Germany, and Italy, while for the case of Switzerland and the UK, the conditional volatility is predicted by US and US squared factors (along with a single Euro factor for the case of the UK). The VIX is an important determinant of conditional volatility for all countries. This finding corroborates with the US results in Guo and Whitelaw (2006). The explanatory power of the factors for the volatility is fairly large with adjusted $R^{2}$ values ranging from $43 \%$ to $69 \%$. The explanatory power is much larger in the volatility equation than in the return equation, except for Germany where they are of about the same size. This was not unexpected since first moments of returns are generally more difficult to estimate than second moments (Merton (1980)).

Tables 3 and 4 show the factors that contain significant information about the conditional skewness and the conditional kurtosis. These two risk measures are not so well described by the macro finance factors as the traditional risk measure. The $R^{2}$ statistics are fairly low in all cases and only few factors are significant. It is new to the literature to use macro-finance variables to explain higher-order moments so we do not have any previous findings to compare these results to.

In summary, conditional returns and conditional volatility can be predicted using a relatively small number of factors, their squared terms, and a few other variables. The conditional volatility is better explained by the factors than the conditional return is. The conditional skewness and conditional kurtosis are not well explained by the factors, i.e. the higher order 
moments appear not to be highly related to macro-finance variables.

The conditional returns and conditional risk measures are standardized in the remaining analysis.

\subsection{Choice of Factors}

Table 6 displays the results of risk-return trade-off as it appears when the conditional return and the conditional risk measures are projected upon the different sets of factors, similar to Tables 2 to 5 . For Switzerland and the UK it is important to account for all factors when constructing the conditional return and conditional risk measures because the explanatory power of the risk-return trade-off regression is stronger the more factors that are taken into account. Opposite for France where the best fit is achieved when local and Euro area factors only are considered. Interestingly, for Germany and Italy the model with local factors only achieves the best goodness of fit. Thus, we consider the specifications with the largest $R^{2}$ values (indicated by boldface) as the benchmarks specifications to build further analysis upon.

\subsection{Linear Risk-Return Results}

The benchmark linear regressions without and with the recession indicators (see eq. (3) and (4)) are summarized in Table 7. First we focus on the risk-return trade-off as it appears from the linear model without recession indicators.

The explanatory power of the risk-return trade-off equations differs across the European stock markets. It is largest for Switzerland with an adjusted $R^{2}$ of $62 \%$, followed by Germany (48\%), Italy (35\%), France (34\%), and the UK $(32 \%)$. Overall, the conditional risk measures have a very large explanatory 
power for the conditional returns. For comparison, Ludvigson and $\mathrm{Ng}$ (2007) find an $R^{2}$ for the US of $41 \%$.

The autoregressive dynamics have a positive sign, which is most reasonable. The current conditional volatility has a negative effect upon the conditional return with the lagged conditional volatility having a positive effect. The sign of the effects is opposite to that of the US stock market documented in Ludvigson and Ng (2007). Nevertheless, summing up the coefficients the relation is negative. In this way we find similar total effect to Ludvigson and $\mathrm{Ng}(2007)$.

The new risk measures also play a significant part in the risk-return tradeoff. Large skewness implies that the mass of the distribution is centered at the left of the distribution and that the right tail is longer. Thus, we expect that there is a positive relation between conditional skewness and conditional returns. The risk from the current conditional skewness has a positive influence on the returns for Germany and Italy and no effect for the other countries. Thus, this effect is more or less as expected.

Large kurtosis implies fat tails, so we expect there is a positive relation between conditional kurtosis and conditional returns. The conditional kurtosis has a negative influence upon conditional returns for France and a positive effect for Switzerland and no effects for the other countries. The lagged kurtosis has a negative effect for Germany and Switzerland. Similar to the volatility risk, the kurtosis risk has opposite effects from what is expected.

Generally, the risk-return trade-off in the European stock markets is significantly different between recessions and expansions (except for Switzerland). Still, the explanatory power of the risk-return regressions is only slightly larger in the recession model than in the linear model. Typically the recession coefficients have opposite signs of the normal coefficients. So 
the effects from the risk measures is typically weaker in recessions. Overall, the differences in risk-return trade-off across the business cycles are fairly small. Lustig and Verdelhan (2012) find that there are large differences in the risk-return trade-off across the business cycle, the trade-off being stronger in recessions. So, our results are quite different.

\subsection{Markov Switching Risk-Return Results}

Table 8 shows the results from estimating the Markov switching risk-return trade-off model from eq. (6). We find evidence of two well distinguished states as the $R C M$ 's are small (from 12 to 38). We denote the persistent state 1 the normal state, while state 2 is the unusual state. State 1 applies between $55 \%$ and $76 \%$ of the time. The explanatory power of the Markov switching regressions is high ( $R^{2}$ is above $44 \%$ for all countries) and particularly so for Germany ( $R^{2}$ of $85 \%$ ). For all countries, the explanatory power of the Markov switching model is larger than for the linear model.

As expected, in state 1, the risk-return trade-off is similar to that in the simple linear model. The contemporaneous conditional volatility has a negative effect upon the conditional return, while the coefficient of lagged conditional volatility is positive. The effect from the lagged return itself is positive. The skewness and kurtosis risk variables are only significant in a few cases.

On the other hand, in state 2 the effect from the contemporaneous volatility is still negative but the effect is less strong than in state 1 . The effect from the lagged volatility is unaltered positive. The skewness and kurtosis risk measure are more important in state 2. Still, the signs are not totally in accordance with expectations.

Figure 1 shows the smoothed state probabilities for each of the countries 
as well as their recession periods. The figure stresses that the business cycles are not one-to-one related to the state.

We investigate if a selected set of variables can explain which state the stock market is in. The stock market is in state $j$ when the smoothed state probability exceeds 0.5 , that is when $\xi_{t / T}^{j}>0.5$. We use a probit model for each country where the dependent variable is an indicator for being in state 2 , $\left[\xi_{t / T}^{2}>0.5\right]$ and the independent variables are the country specific recession dummy, the country specific term spread, the country specific dividend yield, and the VIX volatility index (all variables are standardized). The results are shown in Table 9. Combined, the four variables have a fairly high explanatory power with McFadden $R^{2}$ values ranging between $18 \%$ (Germany) and $51 \%$ (Switzerland). State 2 is positively related to the recession indicator. So it is likely that the unusual state overlaps with recession periods. The country specific term spread has a negative effect for Italy, a positive effect for Germany and Switzerland, and no effect for the other two countries. The country specific dividend yield has a negative effect for all countries. The effect from the volatility index is positive except for Switzerland Overall, the variables help explain the state of the stock market. We observe large differences across countries.

\section{Conclusion}

In this paper we add to the risk-return trade-off literature in many ways. First, we broaden the existing literature by analyzing five large European stock markets instead of only considering the US stock market. Second, we construct conditional returns and conditional risk measures using factors that are based upon a large number of macro-finance variables. Third, we 
consider the effect of using local, regional, and global factors and the optimal choice varies across countries. Fourth, we show that there is a strong relation between conditional returns and conditional volatilities. The relation has the opposite sign as for the US. Fifth, we add two new conditional risk measures, namely the conditional skewness and the conditional kurtosis to the riskreturn trade-off analysis. Sixth, the risk-return trade-off differs a little bit across the business cycle. Seventh, the Markov switching model describes the risk-return relationship well. The most common state is similar to what is seen in the simple linear model. The other state has higher residual variance and the relation is either stronger or non-existing. Eighth, we find that certain variables help explain the state of the stock market.

\section{References}

Andersen, T. G., T. Bollerslev, F. X. Diebold, and P. Labys (2003): "Modeling and Forecasting Realized Volatility," Econometrica, 71, $529-626$.

Ang, A., And G. Bekaert (2002): "Regime Switching in Interest Rates," Journal of Business 85 Economic Statistics, 20(2), 163-182.

BAI, J., AND S. NG (2002): "Determining the Number of Factors in Approximate Factor Models," Econometrica, 70(1), 135-172.

Brandt, M. W. (2010): "Measuring the Time-Varying Risk-Return Relaiton from the Cross-Section of Equity Returns," Working Paper, Duke University. 
Christiansen, C., M. Schmeling, and A. Schrimpf (2012): "A Comprehensive Look at Financial Volatility Prediction by Economic Variables," Journal of Applied Econometrics, 27, 956-977.

Ghysels, E., P. Santa-Clara, and R. Valkanov (2005): "There is a Risk-Return Trade-Off After All," Journal of Financial Economics, 76, $509-548$.

Goyal, A., and I. Welch (2008): "A Comprehensive Look at The Empirical Performance of Equity Premium Prediction," The Review of Financial Studies, 21(4), 1455-1508.

Guidolin, M. (2011): "Markov Switching Models in Empirical Finance," in Missing Data Methods: Time-Series Methods and Applications (Advances in Econometrics), ed. by D. M. Drukker, vol. 27, pp. 1-86. Emerald Group Publishing Limited.

Guo, H., and R. F. Whitelaw (2006): "Uncovering the RiskâĂŞReturn Relation in the Stock Market," Journal of Finance, 61, 1433-1463.

Harvey, C., and A. Siddique (2000): "Conditional Skewness in Asset Pricing Tests," Journal of Finance, 55, 1263-1295.

Ludvigson, S. C., and S. NG (2007): "The Empirical Risk-Return Relation: A Factor Analysis Approach," Journal of Financial Economics, 83(1), 171-222.

Lustig, H., and A. Verdelhan (2012): "Business Cycle Variation in the Risk-Return Trade-Off," Journal of Monetary Economics, 59, 35-49.

Merton, R. C. (1973): "An Intertemporal Capital Asset Pricing Model," Econometrica, 41(5), 867-887. 
Merton, R. C. (1980): "On Estimating the Expected Return on the Market: An Exploratory Investigation," Journal of Financial Economics, 8, 323âĂŞ361.

Nyberg, H. (2012): "Risk-Return Tradeoff in U.S. Stock Returns over the Business Cycle," Journal of Financial and Quantitative Analysis, 47(1), $137-158$.

Schrimpf, A., AND Q. WAng (2010): "A Reappraisal of the Leading Indicator Properties of the Yield Curve under Structural Instability," International Journal of Forecasting, 26, 836-857.

Stock, J. H., And M. W. Watson (2002): "Macroeconomic Forecasting Using Diffusion Indexes," Journal of Business and Economic Statistics, 20(2), 147-162.

Theodossiou, P., And C. S. Savva (2013): "Skewness and the Relation between Risk and Return," Working Paper, Cyprus University of Technology. 
Table 1: Summary Statistics for Factors

\begin{tabular}{|c|c|c|c|c|c|c|c|c|c|c|c|c|c|c|}
\hline \multirow[b]{2}{*}{$\mathrm{i}$} & \multicolumn{2}{|c|}{ France } & \multicolumn{2}{|c|}{ Germany } & \multicolumn{2}{|c|}{ Italy } & \multicolumn{2}{|c|}{ Switzerland } & \multicolumn{2}{|c|}{ UK } & \multicolumn{2}{|c|}{ Euro } & \multicolumn{2}{|c|}{ US } \\
\hline & AR1 & $\%$ Acc & AR1 & $\%$ Acc & AR1 & $\%$ Acc & AR1 & $\%$ Acc & AR1 & $\%$ Acc & AR1 & $\%$ Acc & AR1 & $\%$ Acc \\
\hline 1 & 0.20 & 0.38 & 0.37 & 0.32 & 0.12 & 0.27 & 0.80 & 0.33 & 0.18 & 0.32 & 0.22 & $\overline{0.40}$ & 0.43 & 0.30 \\
\hline 2 & 0.74 & 0.54 & 0.48 & 0.46 & 0.11 & 0.44 & 0.38 & 0.50 & 0.61 & 0.53 & 0.87 & 0.55 & 0.64 & 0.48 \\
\hline 3 & 0.13 & 0.62 & 0.11 & 0.57 & 0.08 & 0.58 & 0.28 & 0.61 & 0.82 & 0.66 & 0.10 & 0.66 & 0.03 & 0.61 \\
\hline 4 & 0.13 & 0.69 & -0.03 & 0.66 & 0.07 & 0.67 & 0.32 & 0.70 & -0.09 & 0.75 & 0.21 & 0.74 & 0.80 & 0.71 \\
\hline 5 & -0.18 & 0.76 & 0.43 & 0.74 & 0.07 & 0.75 & 0.04 & 0.77 & 0.43 & 0.80 & 0.03 & 0.80 & 0.22 & 0.78 \\
\hline 6 & -0.07 & 0.82 & 0.00 & 0.81 & 0.19 & 0.81 & 0.14 & 0.82 & 0.07 & 0.84 & -0.10 & 0.85 & 0.17 & 0.83 \\
\hline
\end{tabular}

Notes: The table shows the summary statistics for the factors where AR1 is the first order autocorrelation coefficient and \%Acc is the accumulated fraction of total variation in the data explained by factors. 
Table 2: Return Regressions

\begin{tabular}{|c|c|c|c|c|c|c|c|c|c|c|c|c|c|c|c|}
\hline & \multicolumn{3}{|c|}{ France } & \multicolumn{3}{|c|}{ Germany } & \multicolumn{3}{|c|}{ Italy } & \multicolumn{3}{|c|}{ Switzerland } & \multicolumn{3}{|c|}{ UK } \\
\hline & Local & Euro & Global & Local & Euro & Global & Local & Euro & Global & Local & Euro & Global & Local & Euro & Global \\
\hline constant & 0.007 & 0.007 & 0.031 & 0.008 & 0.007 & 0.006 & 0.014 & -0.011 & -0.016 & 0.037 & 0.040 & 0.039 & 0.009 & 0.009 & 0.035 \\
\hline Local Factor 1 & & & & -0.147 & & & & -0.299 & & & & & 0.211 & 0.211 & \\
\hline Local Factor 2 & -0.334 & -0.334 & & -0.244 & -0.253 & -0.187 & 0.206 & & & 0.268 & 0.329 & & & & \\
\hline Local Factor 3 & -0.267 & -0.267 & -0.206 & & & & -0.297 & -0.221 & -0.410 & & & & & & \\
\hline Local Factor 4 & 0.546 & 0.546 & 0.542 & -0.419 & -0.407 & -0.361 & & & & & & & -0.214 & -0.214 & \\
\hline Local Factor 5 & -0.407 & -0.407 & -0.394 & -0.210 & -0.181 & -0.112 & & & & & & & & & \\
\hline Local Factor 6 & -0.509 & -0.509 & -0.495 & -0.919 & -0.933 & -0.978 & -0.204 & -0.330 & -0.265 & & & & & & \\
\hline Euro Factor 1 & & & & & & & & -0.870 & & & & & & & \\
\hline Euro Factor 6 & & & & & -0.124 & -0.141 & & & & & -0.163 & & & & \\
\hline US Factor 1 & & & -0.624 & & & & & & & & & -0.373 & & & -0.304 \\
\hline US Factor 2 & & & 0.561 & & & 0.165 & & & 0.334 & & & & & & \\
\hline US Factor 3 & & & -0.315 & & & & & & -0.437 & & & -0.347 & & & -0.315 \\
\hline US Factor 5 & & & & & & & & & -0.210 & & & -0.147 & & & \\
\hline US Factor 6 & & & & & & -0.248 & & & & & & & & & \\
\hline $\begin{array}{l}(\text { Local Factor 2) } \\
(\text { Local Factor } 3)^{2}\end{array}$ & & & & & & & 5.372 & 6.594 & $\begin{array}{l}5.194 \\
2.941\end{array}$ & & & & -13.343 & -13.343 & \\
\hline$(\text { Local Factor } 4)^{2}$ & -2.426 & -2.426 & -2.108 & & & & & & & -2.907 & -3.082 & -3.870 & -3.490 & -3.490 & -4.286 \\
\hline$(\text { Local Factor } 6)^{2}$ & & & & -1.625 & -1.547 & -1.314 & & & & & & & & & \\
\hline $\begin{array}{l}\text { (Euro Factor } 1)^{2} \\
(\text { Euro Factor } 2)^{2}\end{array}$ & & & & & & & & & $\begin{array}{r}8.202 \\
-3.308\end{array}$ & & $\begin{array}{l}5.0313 \\
-2.121\end{array}$ & -1.434 & & & \\
\hline $\begin{array}{l}\text { (Euro Factor 2) } \\
(\text { Euro Factor } 4)^{2}\end{array}$ & & & & & & & & & 1.507 & & 1.107 & & & & \\
\hline$(\text { US Factor } 3)^{2}$ & & & & & & -3.155 & & & & & & & & & \\
\hline$(\text { US Factor } 4)^{2}$ & & & & & & 2.178 & & & & & & & & & \\
\hline Term Spread & & & 0.005 & -0.006 & -0.006 & -0.006 & & & & & & & & & \\
\hline Dividend Yield & & & -0.010 & & & & -0.008 & -0.008 & -0.009 & -0.015 & -0.0178 & -0.014 & & & -0.008 \\
\hline $\mathrm{y}_{\mathrm{t}-1}$ & -0.271 & -0.271 & -0.538 & -0.106 & & -0.122 & & -0.126 & -0.248 & & & & & & \\
\hline$\overline{\mathrm{BIC}}$ & -6.09 & -6.09 & -6.18 & -6.64 & -6.67 & -6.71 & -5.48 & -5.61 & -5.49 & -6.07 & -6.07 & -6.13 & $\begin{array}{c}-6.14 \\
\end{array}$ & $\begin{array}{l}-6.14 \\
\end{array}$ & -6.11 \\
\hline $\mathrm{R}^{2}$ & 0.38 & 0.38 & 0.47 & 0.66 & 0.66 & 0.70 & 0.10 & 0.15 & 0.20 & 0.07 & 0.13 & 0.16 & 0.06 & 0.06 & 0.09 \\
\hline
\end{tabular}

Notes: The table shows the coefficients from the return regression in eq. (2). The models are selected according to BIC. All coefficients are significant at the $1 \%$ level. 
Table 3: Volatility Regressions

\begin{tabular}{|c|c|c|c|c|c|c|c|c|c|c|c|c|c|c|c|}
\hline & \multicolumn{3}{|c|}{ France } & \multicolumn{3}{|c|}{ Germany } & \multicolumn{3}{|c|}{ Italy } & \multicolumn{3}{|c|}{ Switzerland } & \multicolumn{3}{|c|}{ UK } \\
\hline & Local & Euro & Global & Local & Euro & Global & Local & Euro & Global & Local & Euro & Global & Local & Euro & Global \\
\hline constant & 0.015 & 0.014 & 0.019 & 0.022 & 0.018 & 0.020 & 0.019 & 0.019 & 0.029 & 0.006 & 0.012 & 0.017 & 0.009 & 0.010 & 0.014 \\
\hline Local Factor 1 & & 0.059 & & & 0.050 & 0.083 & 0.098 & & & & & & -0.087 & & \\
\hline Local Factor 2 & 0.053 & & & & -0.070 & -0.095 & & 0.098 & & & & & & & \\
\hline Local Factor 3 & & & & 0.058 & & & 0.080 & 0.080 & 0.093 & & & & & -1.659 & \\
\hline Local Factor 4 & -0.140 & -0.147 & -0.130 & 0.057 & & & & 1.558 & & & & & & 1.594 & \\
\hline Local Factor 5 & & 0.051 & 0.086 & & & & & & & -0.066 & & & & & \\
\hline Local Factor 6 & 0.122 & 0.121 & 0.153 & 0.148 & 0.145 & 0.173 & & & & & & & -0.065 & & \\
\hline Euro Factor 6 & & & & & & & & & & & & & & & -0.053 \\
\hline US Factor 1 & & & & & & -0.171 & & & & & & & & & \\
\hline US Factor 2 & & & -0.116 & & & & & & -0.095 & & & -0.158 & & & -0.110 \\
\hline US Factor 5 & & & -0.113 & & & & & & & & & & & & \\
\hline US Factor 6 & & & -0.055 & & & 0.079 & & & & & & & & & \\
\hline$\left(\right.$ Local Factor 1) ${ }^{2}$ & & & & 1.107 & 1.421 & & & & & 1.767 & 1.780 & & & & \\
\hline $\begin{array}{l}(\text { Local Factor } 2)^{2} \\
(\text { Local Factor } 3)^{2}\end{array}$ & 0.976 & 1.053 & & & & 0.711 & & & & -1.281 & -2.180 & -1.702 & $\begin{array}{r}6.134 \\
-1.255\end{array}$ & & -1.53 \\
\hline (Local Factor 4$)^{2}$ & 1.604 & 1.559 & 1.397 & & 1.220 & 1.250 & 1.558 & & 1.610 & 1.179 & 1.442 & 1.108 & 1.214 & & 1.559 \\
\hline$(\text { Local Factor } 5)^{2}$ & 0.676 & 0.685 & 0.565 & & & & & & & & & & & & \\
\hline$\left(\right.$ Local Factor 6) ${ }^{2}$ & & & & 2.289 & $\begin{array}{r}2.245 \\
-1082\end{array}$ & $\begin{array}{r}2.315 \\
-0945\end{array}$ & & & & & 1039 & & & 1105 & \\
\hline $\begin{array}{l}\text { (Euro Factor 2) } \\
(\text { Euro Factor } 3)^{2}\end{array}$ & & -0.579 & & & -1.082 & -0.945 & & & & & 1.039 & & & 1.105 & 0.128 \\
\hline$(\text { US Factor } 1)^{2}$ & & & -2.590 & & & -4.402 & & & & & & & & & -2.979 \\
\hline$(\text { US Factor } 2)^{2}$ & & & 2.023 & & & 2.073 & & & 1.887 & & & 2.468 & & & 1.389 \\
\hline VIX & 0.085 & 0.090 & 0.086 & 0.143 & 0.150 & 0.149 & 0.058 & 0.058 & & 0.114 & 0.084 & 0.102 & 0.078 & 0.067 & 0.069 \\
\hline $\mathrm{RV}_{\mathrm{t}-1}$ & 0.246 & 0.260 & 0.176 & & & & 0.398 & 0.398 & 0.388 & 0.218 & 0.221 & & 0.394 & 0.409 & 0.276 \\
\hline $\mathrm{BIC}$ & $\begin{array}{l}-7.96 \\
\end{array}$ & $\begin{array}{l}-7.94 \\
\end{array}$ & -8.00 & -8.08 & -8.10 & -8.12 & -7.56 & -7.56 & -7.59 & -7.67 & -7.76 & -7.78 & -8.00 & -7.94 & -7.95 \\
\hline $\mathrm{R}^{2}$ & 0.57 & 0.58 & 0.61 & 0.64 & 0.66 & 0.69 & 0.40 & 0.40 & 0.42 & 0.37 & 0.37 & 0.43 & 0.47 & 0.48 & 0.52 \\
\hline
\end{tabular}

Notes: The table shows the coefficients from the volatility regression in eq. (2). The models are selected according to BIC. All coefficients are significant at the $1 \%$ level. 
Table 4: Skewness Regressions

\begin{tabular}{|c|c|c|c|c|c|c|c|c|c|c|c|c|c|c|c|}
\hline & \multicolumn{3}{|c|}{ France } & \multicolumn{3}{|c|}{ Germany } & \multicolumn{3}{|c|}{ Italy } & \multicolumn{3}{|c|}{ Switzerland } & \multicolumn{3}{|c|}{ UK } \\
\hline & Local & Euro & Global & Local & Euro & Global & Local & Euro & Global & Local & Euro & Global & Local & Euro & Global \\
\hline $\begin{array}{l}\text { constant } \\
\text { Local Factor } 1\end{array}$ & -0.020 & -0.020 & -0.020 & -0.176 & -0.176 & $\overline{-0.176}$ & 0.015 & -0.044 & 0.147 & -0.413 & -0.413 & $\begin{array}{r}-0.243 \\
1.966\end{array}$ & -0.063 & -0.063 & -0.066 \\
\hline Local Factor 2 & & & & & & & & & & & & & 4.925 & 4.925 & 4.423 \\
\hline Euro Factor 4 & & & & & & & & -1.249 & -1.283 & & & & & & \\
\hline US Factor 1 & & & & & & & & & & & & 118.996 & & & \\
\hline US Factor 2 & & & & & & & & & -2.243 & & & & & & \\
\hline US Factor 3 & & & & & & & & & -2.891 & & & & & & \\
\hline US Factor 4 & & & & & & & & & & & & & & & -1.800 \\
\hline US Factor 5 & & & & & & & & & & & & & & & 1.747 \\
\hline US Factor 6 & & & & & & & & & & & & & & & -1.578 \\
\hline$(\text { Local Factor } 1)^{2}$ & 26.125 & 26.125 & 26.125 & & & & & & & & & & & & \\
\hline$(\text { Local Factor } 2)^{2}$ & & & & 26.186 & 26.186 & 26.186 & & & & & & & & & \\
\hline $\begin{array}{l}(\text { Local Factor } 3)^{2} \\
(\text { Local Factor } 4)^{2}\end{array}$ & -26.485 & -26.485 & -26.485 & & & & & & & & & & & & \\
\hline$(\text { Local Factor } 5)^{2}$ & & & & & & & & & & 32.307 & 32.307 & & & & \\
\hline$(\text { Local Factor } 6)^{2}$ & & & & 24.046 & 24.046 & 24.046 & & & & & & & & & \\
\hline$(\text { US Factor } 1)^{2}$ & & & & & & & & & & & & 118.996 & & & \\
\hline$(\text { US Factor } 4)^{2}$ & & & & & & & & & & & & 47.364 & & & \\
\hline$(\text { US Factor } 5)^{2}$ & & & & & & & & & & & & -24.996 & & & \\
\hline $\begin{array}{l}\text { Dividend Yield } \\
\text { VIX }\end{array}$ & & & & & & & -0.047 & & -0.061 & & & 0.051 & & & \\
\hline VIX & & & & & & & & & & 1.003 & 1.003 & & & & \\
\hline$\overline{\mathrm{BIC}}$ & -1.22 & -1.22 & -1.22 & 1.14 & 1.14 & $\overline{-1.14}$ & -1.10 & -1.10 & -1.08 & -1.14 & -1.14 & $\overline{-1.11}$ & -1.23 & -1.23 & -1.22 \\
\hline $\mathrm{R}^{2}$ & 0.03 & 0.03 & 0.03 & 0.05 & 0.05 & 0.05 & 0.01 & 0.01 & 0.04 & 0.03 & 0.03 & 0.05 & 0.02 & 0.02 & 0.05 \\
\hline
\end{tabular}

Notes: The table shows the coefficients from the skewness regression in eq. (2). The models are selected according to BIC. All coefficients are significant at the $1 \%$ level. 
Table 5: Kurtosis Regressions

\begin{tabular}{|c|c|c|c|c|c|c|c|c|c|c|c|c|c|c|c|}
\hline & \multicolumn{3}{|c|}{ France } & \multicolumn{3}{|c|}{ Germany } & \multicolumn{3}{|c|}{ Italy } & \multicolumn{3}{|c|}{ Switzerland } & \multicolumn{3}{|c|}{ UK } \\
\hline & Local & Euro & Global & Local & Euro & Global & Local & Euro & Global & Local & Euro & Global & Local & Euro & Global \\
\hline constant & 3.057 & 3.057 & 3.057 & 3.155 & 3.222 & $\overline{3.222}$ & 2.905 & 2.904 & 2.904 & 2.894 & 2.894 & 2.974 & 2.705 & 2.701 & 2.673 \\
\hline Local Factor 1 & & & & & & & -6.372 & -6.380 & -6.380 & & & & & & \\
\hline Local Factor 2 & & & & & -5.516 & -5.516 & & & & & & & & & \\
\hline Euro Factor 4 & & & & & & & & 2.873 & 2.873 & & & & & & \\
\hline Euro Factor 5 & & & & & 6.322 & 6.322 & & & & & & & & & \\
\hline $\begin{array}{l}\text { US Factor } 1 \\
\text { US Factor } 4\end{array}$ & & & & & & & & & & & & -8.642 & & & -5.266 \\
\hline $\begin{array}{l}\text { US Factor } 4 \\
(\text { Local Factor } 3)^{2}\end{array}$ & & & & & & & & & & & & & -50.955 & & $\begin{array}{r}3.213 \\
-53.038\end{array}$ \\
\hline$($ Local Factor 5) & & & & & & & 64.57 & 66.221 & 66.221 & 57.967 & 57.967 & & & & \\
\hline$\left(\right.$ Local Factor 6) ${ }^{2}$ & -44.514 & -44.514 & -44.514 & & & & & & & & & & 75.538 & 47.627 & 85.053 \\
\hline $\begin{array}{l}\text { Euro Factor } 5)^{2} \\
\text { Term Spread }\end{array}$ & -0.122 & -0.122 & -0.122 & -0.184 & $\begin{array}{r}-65.770 \\
-0.187\end{array}$ & $\begin{array}{r}-65.770 \\
-0.187\end{array}$ & & & & & & & & & \\
\hline $\mathrm{BIC}$ & 0.13 & 0.13 & 0.13 & 0.59 & 0.60 & 0.60 & 0.40 & 0.40 & 0.40 & 0.52 & 0.52 & $\overline{0.52}$ & -0.10 & -0.11 & -0.09 \\
\hline $\mathrm{R}^{2}$ & 0.02 & 0.02 & 0.02 & 0.03 & 0.06 & 0.06 & 0.03 & 0.04 & 0.04 & 0.01 & 0.01 & 0.02 & 0.04 & 0.03 & 0.06 \\
\hline
\end{tabular}

Notes: The table shows the coefficients from the kurtosis regression in eq. (2). The models are selected according to BIC. All coefficients are significant at the $1 \%$ level. 
Table 6: Linear Regressions Using Different Factors

\begin{tabular}{|c|c|c|c|c|}
\hline France & Raw Data & Local Factors & Euro Factors & Global Factors \\
\hline Cons & 0.00 & 0.01 & 0.01 & 0.01 \\
\hline $\operatorname{Ret}(-1)$ & 0.00 & $0.24 * * *$ & $0.27^{* * *}$ & $0.23 * * *$ \\
\hline Vol & $-0.64 * * *$ & $-0.56 * * *$ & $-0.63 * * *$ & $-0.67 * * *$ \\
\hline $\operatorname{Vol}(-1)$ & $0.38 * * *$ & $0.42 * * *$ & $0.47 * * *$ & $0.49 * * *$ \\
\hline $\mathrm{Sk}$ & -0.05 & -0.15 & -0.14 & -0.11 \\
\hline $\operatorname{Sk}(-1)$ & $-0.12 *$ & -0.01 & 0.00 & -0.03 \\
\hline $\mathrm{Ku}$ & 0.05 & $-0.27 * * *$ & $-0.23 * * *$ & -0.14 \\
\hline $\mathrm{Ku}(-1)$ & -0.14 & 0.09 & 0.08 & 0.00 \\
\hline $\operatorname{Adj} R^{2}$ & 0.24 & 0.29 & 0.34 & 0.34 \\
\hline Germany & Raw Data & Local Factors & Euro Factors & Global Factors \\
\hline Cons & 0.00 & 0.01 & 0.01 & 0.01 \\
\hline $\operatorname{Ret}(-1)$ & 0.01 & 0.08 & 0.05 & 0.05 \\
\hline Vol & $-0.61 * * *$ & $-1.11 * * *$ & $-1.01 * * *$ & $-0.36 * * *$ \\
\hline $\operatorname{Vol}(-1)$ & $0.31 * * *$ & $0.73^{* * *}$ & $0.62 * * *$ & 0.16 \\
\hline $\mathrm{Sk}$ & 0.02 & $0.27 * * *$ & $0.25 * * *$ & -0.03 \\
\hline $\operatorname{Sk}(-1)$ & 0.04 & -0.08 & -0.07 & 0.02 \\
\hline $\mathrm{Ku}$ & -0.03 & -0.06 & -0.04 & -0.09 \\
\hline $\mathrm{Ku}(-1)$ & $-0.10 *$ & $-0.12 * *$ & $-0.14 * * *$ & $-0.11 *$ \\
\hline $\operatorname{Adj} R^{2}$ & 0.24 & 0.48 & 0.41 & 0.11 \\
\hline
\end{tabular}




\begin{tabular}{l} 
Italy \\
\hline Cons \\
Ret(-1) \\
Vol \\
Vol(-1) \\
$\mathrm{Sk}$ \\
$\mathrm{Sk}(-1)$ \\
$\mathrm{Ku}$ \\
$\mathrm{Ku}(-1)$ \\
Adj $\mathrm{R}^{2}$
\end{tabular}

\begin{tabular}{c} 
Raw Data \\
\hline 0.00 \\
0.10 \\
$-0.47 * *$ \\
0.31 *** \\
0.17 ** \\
-0.08 \\
0.04 \\
$-0.13 * *$ \\
0.15
\end{tabular}

\begin{tabular}{c} 
Local Factors \\
\hline 0.01 \\
$0.29 * * *$ \\
$-0.55 * *$ \\
$0.32^{* * *}$ \\
$0.22^{* * *}$ \\
$0.16^{* * *}$ \\
0.00 \\
-0.06 \\
0.35
\end{tabular}

Euro Factors

0.00

$-0.35 * * * \quad-0.30 * * *$

$0.21 * \quad 0.08$

0.02

$0.26^{* * *} \quad 0.19^{* * *}$

$0.07-0.10$

$\begin{array}{ll}0.07 & -0.08\end{array}$

$0.31 \quad 0.24$

\begin{tabular}{c} 
Raw Data \\
\hline 0.00 \\
0.02 \\
-0.62 *** \\
$0.24^{* * *}$ \\
-0.08 \\
$0.23^{* * *}$ \\
$0.19 * *$ \\
-0.07 \\
0.35
\end{tabular}

Local Factors

0.02

$0.68 * * *$

$-0.29 * * *$

$0.21 * * *$

$-0.09 *$

$0.15^{* * *}$

$-0.09$

$-0.05$

0.54

Raw Data
0.00

Local Factors

$-0.01$

$0.38^{* * *}$

$-0.70 * * *$

$0.45^{* * *}$

$-0.01$

0.00

$0.22 * * *$

$-0.01$

0.32
Euro Factors

0.01

$0.54 * * *$

$-0.56 * * *$

$0.32 * * *$

$-0.08$

$0.16 * * *$

$-0.02$

$-0.06$

0.54

Euro Factors

-0.01
0.38

0.38
-0.62

0.36

$-0.01$

$-0.02$

0.22

$-0.02$

0.34
Global Factors

0.00

$-0.33 * * *$

$0.30 * * *$

$-0.02$

0.00

$0.59 * * *$

$-0.25 * * *$

0.62

Global Factors

$-0.01$

$0.51 * * *$

$-0.29 * * *$

0.33 ***

0.06

$-0.04$

$-0.06$

0.11

0.36
$0.57 * * *$

0.27

Notes: The table shows the results from the regressions in eq. (3) using various restrictions on the factors in eq. (2). $* / * * / * * *$ indicates that the parameter is significant at the $10 \% / 5 \% / 1 \%$ level. 
Table 7: Linear Risk-Return Regressions

\begin{tabular}{l}
\hline Cons \\
Ret $(-1)$ \\
Vol \\
Vol $(-1)$ \\
Sk \\
Sk(-1) \\
$\mathrm{Ku}$ \\
$\mathrm{Ku}(-1)$ \\
$\mathrm{D}$ \\
$\mathrm{D}^{*} \mathrm{Ret}(-1)$ \\
$\mathrm{D}^{*}$ Vol \\
$\mathrm{D}^{*} \mathrm{Vol}(-1)$ \\
$\mathrm{D}^{*} \mathrm{Sk}$ \\
$\mathrm{D}^{*} \mathrm{Sk}(-1)$ \\
$\mathrm{D}^{*} \mathrm{Ku}$ \\
$\mathrm{D}^{*} \mathrm{Ku}(-1)$ \\
\hline Adj-R \\
BIC \\
Wald test stat for all D's=0
\end{tabular}

\begin{tabular}{|c|c|c|c|c|c|}
\hline \multicolumn{2}{|c|}{ France } & \multicolumn{2}{|c|}{ Germany } & \multicolumn{2}{|c|}{ Italy } \\
\hline 0.01 & 0.03 & 0.01 & 0.00 & 0.01 & 0.03 \\
\hline $0.27 * * *$ & $0.31 * * *$ & 0.08 & $0.19 * * *$ & $0.29 * * *$ & 0.37 \\
\hline$-0.63 * * *$ & $-0.73 * * *$ & $-1.11 * * *$ & $-1.24 * * *$ & $-0.55 * * *$ & -0.51 \\
\hline $0.47 * * *$ & $0.62 * * *$ & $0.73^{* * *}$ & $1.00 * * *$ & $0.32 * * *$ & 0.34 \\
\hline-0.14 & -0.11 & $0.27 * * *$ & $0.27 * * *$ & $0.22 * * *$ & 0.14 \\
\hline 0.00 & 0.00 & -0.08 & -0.22 *** & $0.16 * * *$ & 0.12 \\
\hline$-0.23 * * *$ & -0.13 & -0.06 & -0.07 & 0.00 & -0.01 \\
\hline \multirow[t]{9}{*}{0.08} & 0.05 & $-0.12 * *$ & $-0.10 *$ & -0.06 & 0.05 \\
\hline & 0.35 & & 0.03 & & -0.34 \\
\hline & 0.03 & & $-0.34 * * *$ & & -0.27 \\
\hline & $0.40 * * *$ & & 0.28 & & -0.48 \\
\hline & $-0.37 * * *$ & & -0.56 *** & & 0.42 \\
\hline & 0.16 & & -0.03 & & 0.35 \\
\hline & -0.37 & & $0.27^{* * *}$ & & 0.00 \\
\hline & $-0.64 * * *$ & & -0.08 & & -0.10 \\
\hline & -0.23 & & -0.06 & & -0.47 \\
\hline 0.34 & 0.37 & 0.48 & 0.51 & 0.35 & 0.42 \\
\hline \multirow[t]{2}{*}{-0.32} & -0.24 & -0.57 & -0.49 & -0.35 & -0.34 \\
\hline & $27.62 \quad * * *$ & & $11.81^{* *}$ & & 37.93 *** \\
\hline
\end{tabular}

\begin{tabular}{rr}
\multicolumn{2}{c}{ Switzerland } \\
\hline 0.00 & 0.00 \\
$0.57 * * *$ & $0.61 * * *$ \\
$-0.33^{* * *}$ & $-0.32 * * *$ \\
$0.30 * * *$ & $0.27 * * *$ \\
-0.02 & 0.01 \\
0.00 & 0.01 \\
$0.59 * * *$ & $0.59 * * *$ \\
$-0.25 * * *$ & $-0.25 * * *$ \\
& -0.04 \\
& -0.09 \\
& -0.03 \\
& 0.04 \\
& -0.07 \\
& 0.00 \\
& 0.00 \\
& -0.03 \\
\hline 0.62 & 0.61 \\
-0.86 & -0.72 \\
& 6.82
\end{tabular}

\begin{tabular}{rr}
\multicolumn{2}{c}{$\mathrm{UK}$} \\
\hline-0.01 & -0.02 \\
$0.51 * * *$ & $0.48 * * *$ \\
$-0.29 * * *$ & $-0.40 * * *$ \\
$0.33 * * *$ & $0.39 * * *$ \\
0.06 & 0.04 \\
-0.04 & -0.06 \\
-0.06 & -0.25 \\
0.11 & 0.15 \\
& $0.02 * *$ \\
& 0.08 \\
& 0.31 \\
& -0.21 \\
& 0.02 \\
& -0.08 \\
& 0.37 \\
& -0.13 \\
\hline 0.36 & 0.37 \\
-0.35 & -0.20 \\
& $9.93 * *$
\end{tabular}

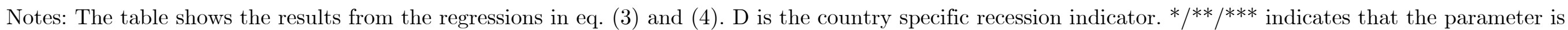
significant. France: European factors. Germany: local factors. Italy: local factors. Switzerland: global factors. UK: global factors. 
Table 8: Markow Switching Risk-Return Regressions

\begin{tabular}{|c|c|c|c|c|c|}
\hline & France & Germany & Italy & Switzerland & UK \\
\hline \multicolumn{6}{|l|}{ Regime 1} \\
\hline Cons & $-0.28 * * *$ & $-0.37 * * *$ & $-0.13 * *$ & $-0.28 * * *$ & $-0.20 *$ \\
\hline $\operatorname{Ret}(-1)$ & $0.20 * * *$ & 0.02 & $0.45 * * *$ & $0.31 * * *$ & $0.59 * * *$ \\
\hline Vol & $-1.13 * * *$ & $-1.00 * * *$ & $-0.46 * * *$ & $-0.48 * * *$ & $-0.44 * *$ \\
\hline $\operatorname{Vol}(-1)$ & $0.70 * * *$ & $0.46 * * *$ & 0.11 & $0.27 * * *$ & 0.19 \\
\hline $\mathrm{Sk}$ & 0.00 & $0.11 * * *$ & 0.08 & 0.02 & 0.06 \\
\hline $\operatorname{Sk}(-1)$ & 0.05 & $0.08 *$ & $0.28 * * *$ & -0.05 & -0.10 \\
\hline $\mathrm{Ku}$ & -0.10 & 0.08 & 0.00 & $0.43 * * *$ & -0.05 \\
\hline $\mathrm{Ku}(-1)$ & 0.04 & $-0.19 * * *$ & -0.02 & -0.05 & 0.09 \\
\hline$\sigma$ & $0.22 * * *$ & $0.24 * * *$ & $0.37 * * *$ & $0.34 * * *$ & $0.91 * * *$ \\
\hline \multicolumn{6}{|l|}{ Regime 2} \\
\hline Cons & $0.47 * * *$ & $0.67 * * *$ & $0.62 * * *$ & $0.55 * * *$ & $0.21 * * *$ \\
\hline $\operatorname{Ret}(-1)$ & 0.11 & $-0.13 * * *$ & -0.05 & $0.18 * *$ & $0.24 * * *$ \\
\hline Vol & $-0.40 * * *$ & $-0.54 * * *$ & $-0.42 * * *$ & $-0.21 * * *$ & $-0.27 * * *$ \\
\hline $\operatorname{Vol}(-1)$ & 0.14 & $0.37 * * *$ & $0.75 * *$ & $0.19 * * *$ & $0.39 * * *$ \\
\hline $\mathrm{Sk}$ & $-0.33 * * *$ & $0.85 * * *$ & 0.24 & -0.06 & 0.04 \\
\hline $\operatorname{Sk}(-1)$ & $-0.14 * * *$ & $-0.20 * * *$ & $-0.22 *$ & $0.11^{* *}$ & $-0.15 * * *$ \\
\hline $\mathrm{Ku}$ & $-0.29 * * *$ & $0.07 *$ & -0.07 & $0.58 * * *$ & $0.14 * * *$ \\
\hline $\mathrm{Ku}(-1)$ & 0.00 & -0.02 & -0.03 & 0.10 & 0.08 \\
\hline$\sigma$ & 0.79 *** & $0.13 * * *$ & $0.39 * * *$ & 0.16 *** & $0.21 * * *$ \\
\hline $\mathrm{p} 11$ & $0.94^{* * *}$ & $0.78^{* * *}$ & $0.94^{* * *}$ & $0.97^{* * *}$ & $0.92^{* * *}$ \\
\hline p22 & $0.90 * * *$ & $0.73^{* * *}$ & $0.81 * * *$ & $0.96 * * *$ & $0.91 * * *$ \\
\hline $\mathrm{p}(\mathrm{s}(\mathrm{t})=1)$ & 0.62 & 0.55 & 0.75 & 0.63 & 0.52 \\
\hline $\mathrm{E}$ (Duration regime 1 ) & 15.9 & 4.5 & 15.8 & 39.9 & 12.1 \\
\hline $\mathrm{E}$ (Duration regime 2 ) & 9.9 & 3.6 & 5.4 & 23.2 & 11.3 \\
\hline $\operatorname{Adj} R^{2}$ & 0.61 & 0.85 & 0.65 & 0.74 & 0.44 \\
\hline $\mathrm{RCM}$ & 23.3 & 37.3 & 33.7 & 12.7 & 34.1 \\
\hline
\end{tabular}

Notes: The tables shows the results from the model in eq. (6).*/**/*** indicates that the coefficient is significant at the 10\%/5\%/1\% level. France: European factors.

Germany: local factors. Italy: local factors. Switzerland: global factors. UK: global factors. 
Table 9: Probit Models for State 2

\begin{tabular}{|c|c|c|c|c|c|}
\hline & France & Germany & Italy & Switzerland & UK \\
\hline cons & $-0.57^{* * *}$ & $-0.19^{* *}$ & $-1.13^{* * *}$ & $-0.97^{* * *}$ & $-0.25 * * *$ \\
\hline D (recession) & $0.98 * * *$ & $0.44 *$ & $0.73 * *$ & $0.69 * * *$ & $1.52 * * *$ \\
\hline Term Spread & -0.08 & $0.43^{* * *}$ & $-0.35 * * *$ & $0.98 * * *$ & -0.11 \\
\hline Dividen Yield & $-0.29 * * *$ & $-0.57 * * *$ & $-0.75 * * *$ & $-1.17 * * *$ & $-0.69 * * *$ \\
\hline VIX & $0.76 * * *$ & $0.25 * * *$ & $0.22 * *$ & $-0.30 * * *$ & 0.09 \\
\hline McFadden $\mathrm{R}^{2}$ & 0.21 & 0.18 & 0.19 & 0.51 & 0.18 \\
\hline
\end{tabular}

Notes: The tables shows the results from the probit model for the indicator variable for state 2. $* * * / * * *$ indicates that the coefficient is significant at the $10 \% / 5 \% / 1 \%$ level. France: European factors. Germany: local factors. Italy: local factors.

Switzerland: global factors. UK: global factors. 
Figure 1: Smoothed Probability of State 2

France

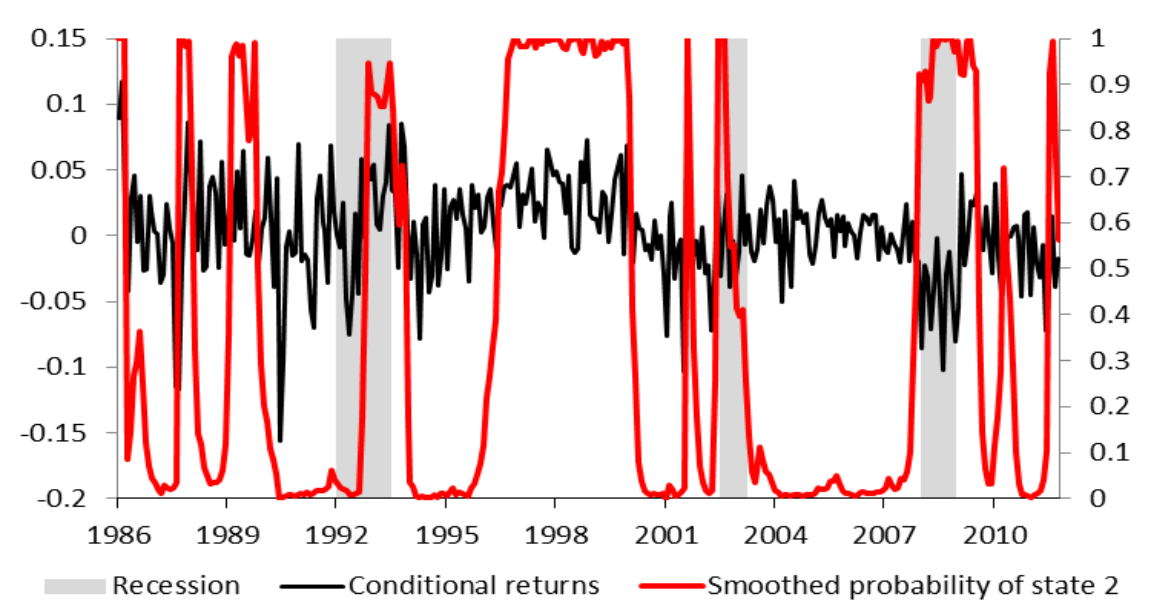

Italy

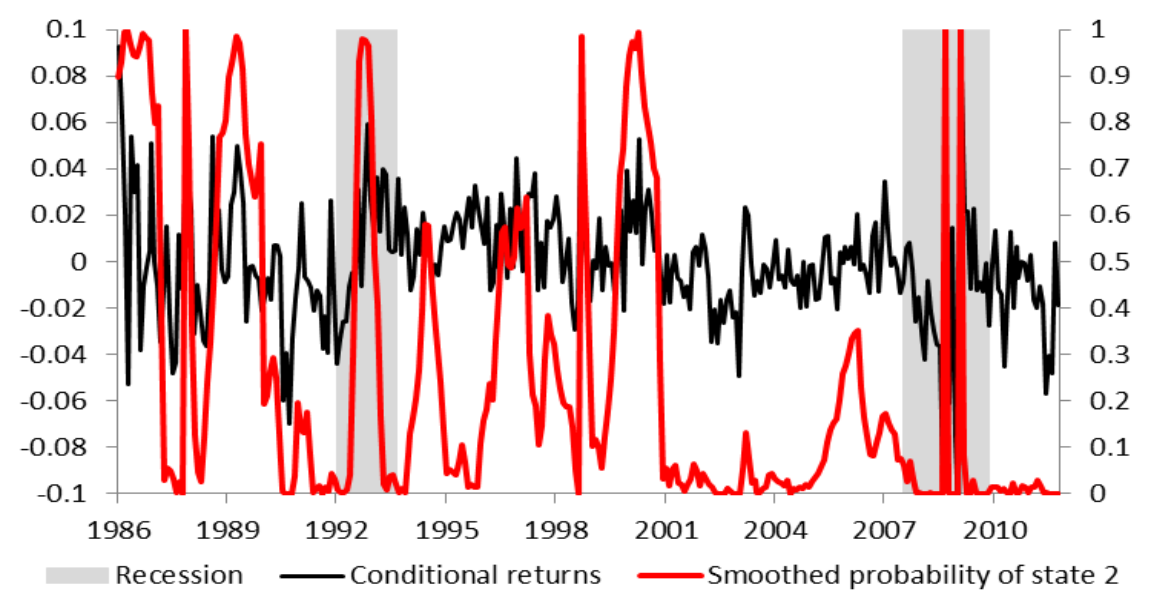

Germany

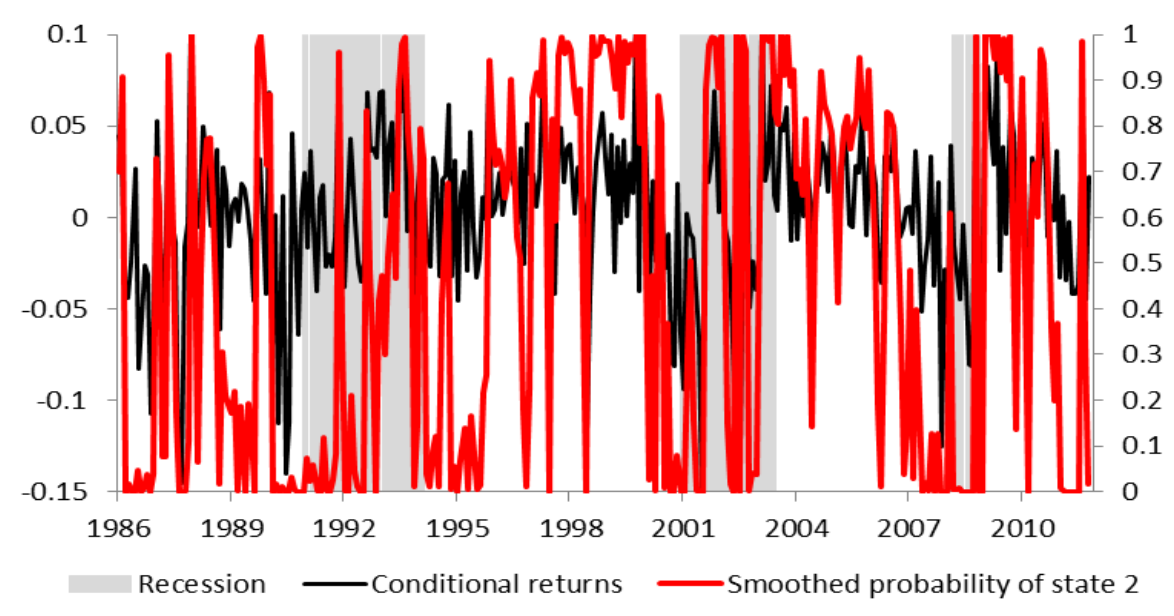

Switzerland

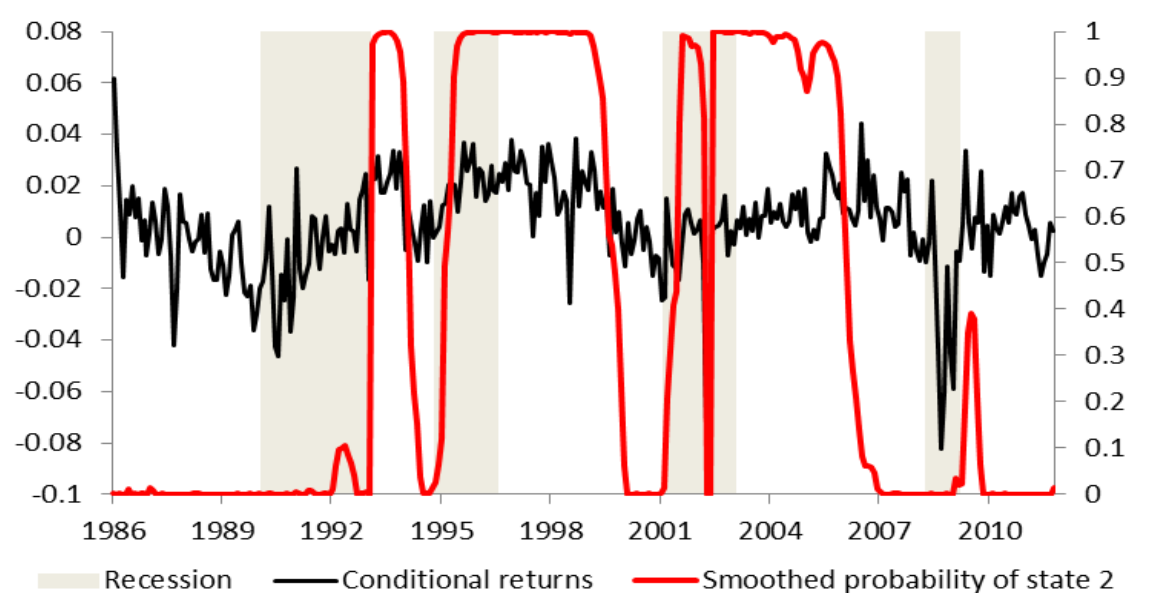




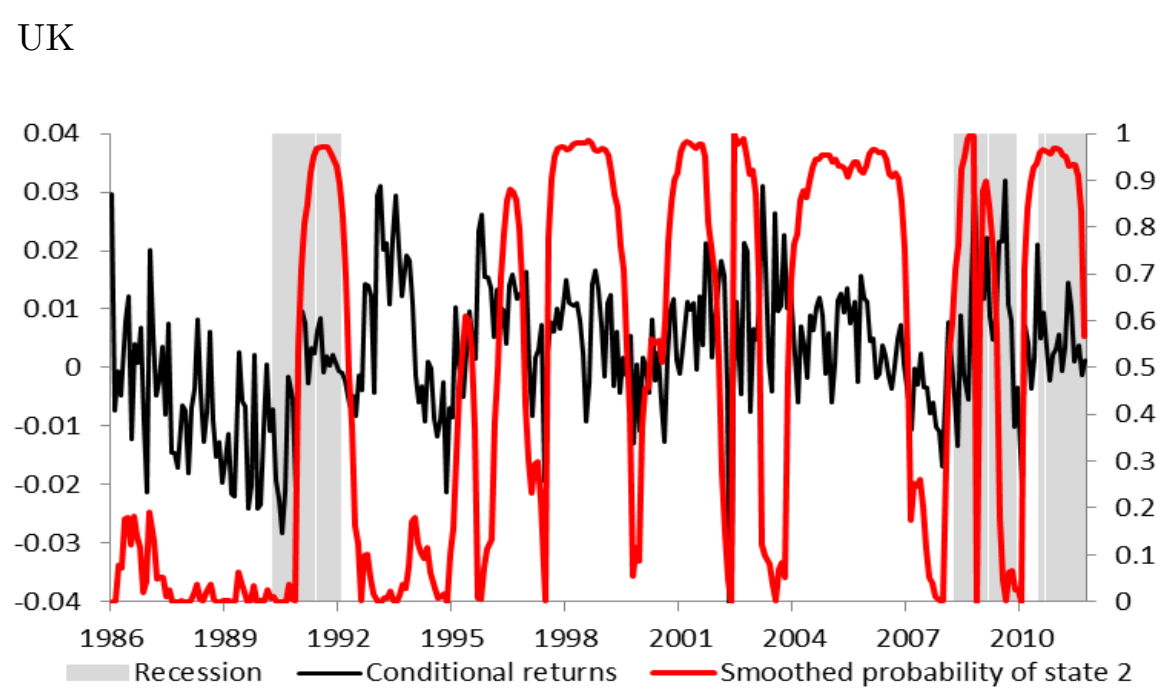


2013-14: Charlotte Christiansen, Jonas Nygaard Eriksen and Stig V. Møller: Forecasting US Recessions: The Role of Sentiments

2013-15: $\quad$ Ole E. Barndorff-Nielsen, Mikko S. Pakkanen and Jürgen Schmiegel: Assessing Relative Volatility/Intermittency/Energy Dissipation

2013-16: $\quad$ Peter Exterkate, Patrick J.F. Groenen, Christiaan Heij and Dick van Dijk: Nonlinear Forecasting With Many Predictors Using Kernel Ridge Regression

2013-17: $\quad$ Daniela Osterrieder: Interest Rates with Long Memory: A Generalized Affine Term-Structure Model

2013-18: $\quad$ Kirstin Hubrich and Timo Teräsvirta: Thresholds and Smooth Transitions in Vector Autoregressive Models

2013-19: $\quad$ Asger Lunde and Kasper V. Olesen: Modeling and Forecasting the Volatility of Energy Forward Returns - Evidence from the Nordic Power Exchange

2013-20: $\quad$ Anders Bredahl Kock: Oracle inequalities for high-dimensional panel data models

2013-21: $\quad$ Malene Kallestrup-Lamb, Anders Bredahl Kock and Johannes Tang Kristensen: Lassoing the Determinants of Retirement

2013-22: Johannes Tang Kristensen: Diffusion Indexes with Sparse Loadings

2013-23: $\quad$ Asger Lunde and Anne Floor Brix: Estimating Stochastic Volatility Models using Prediction-based Estimating Functions

2013-24: $\quad$ Nima Nonejad: A Mixture Innovation Heterogeneous Autoregressive Model for Structural Breaks and Long Memory

2013-25: Nima Nonejad: Time-Consistency Problem and the Behavior of US Inflation from 1970 to 2008

2013-26: Nima Nonejad: Long Memory and Structural Breaks in Realized Volatility: An Irreversible Markov Switching Approach

2013-27: $\quad$ Nima Nonejad: Particle Markov Chain Monte Carlo Techniques of Unobserved Compdonent Time Series Models Using Ox

2013-28: $\quad$ Ulrich Hounyo, Sílvia Goncalves and Nour Meddahi: Bootstrapping preaveraged realized volatility under market microstructure noise

2013-29: Jiti Gao, Shin Kanaya, Degui Li and Dag Tjøstheim: Uniform Consistency for Nonparametric Estimators in Null Recurrent Time Series

2013-30: Ulrich Hounyo: Bootstrapping realized volatility and realized beta under a local Gaussianity assumption

2013-31 Nektarios Aslanidis, Charlotte Christiansen and Christos S. Savva: Risk-Return Trade-Off for European Stock Markets 